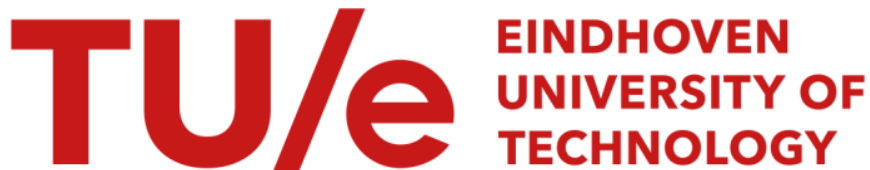

\section{Butanol-diesel blends for partially premixed combustion}

\section{Citation for published version (APA):}

Leermakers, C. A. J., Bakker, P. C., Somers, L. M. T., Goey, de, L. P. H., \& Johansson, B. H. (2013). Butanoldiesel blends for partially premixed combustion. SAE International Journal of Fuels and Lubricants, 6(1), 217229. [2013-01-1683]. https://doi.org/10.4271/2013-01-1683, https://doi.org/10.4271/2013-01-1683

DOI:

10.4271/2013-01-1683

$10.4271 / 2013-01-1683$

Document status and date:

Published: 01/01/2013

\section{Document Version:}

Publisher's PDF, also known as Version of Record (includes final page, issue and volume numbers)

\section{Please check the document version of this publication:}

- A submitted manuscript is the version of the article upon submission and before peer-review. There can be important differences between the submitted version and the official published version of record. People interested in the research are advised to contact the author for the final version of the publication, or visit the $\mathrm{DOI}$ to the publisher's website.

- The final author version and the galley proof are versions of the publication after peer review.

- The final published version features the final layout of the paper including the volume, issue and page numbers.

Link to publication

\section{General rights}

Copyright and moral rights for the publications made accessible in the public portal are retained by the authors and/or other copyright owners and it is a condition of accessing publications that users recognise and abide by the legal requirements associated with these rights.

- Users may download and print one copy of any publication from the public portal for the purpose of private study or research.

- You may not further distribute the material or use it for any profit-making activity or commercial gain

- You may freely distribute the URL identifying the publication in the public portal.

If the publication is distributed under the terms of Article $25 \mathrm{fa}$ of the Dutch Copyright Act, indicated by the "Taverne" license above, please follow below link for the End User Agreement:

www.tue.nl/taverne

Take down policy

If you believe that this document breaches copyright please contact us at:

openaccess@tue.nl

providing details and we will investigate your claim. 


\title{
Butanol-Diesel Blends for Partially Premixed Combustion
}

\author{
C.A.J. Leermakers, P.C. Bakker, L.M.T. Somers, L.P.H. de Goey and B.H. Johansson \\ Eindhoven University of Technology
}

\begin{abstract}
Partially Premixed Combustion has shown the potential of high efficiency, emissions of nitrogen oxides (NOx) and soot below future emissions regulations, and acceptable acoustic noise. Low-octane-number gasoline fuels were shown to be most suitable for this concept, with the reactivity determining the possible load range. Other researchers have used several refinery streams, which might be produced by a refinery if they were required to do so without additional investment.

Some of refinery streams are, however, not expected to be commercially available on the short term. For the present investigation, $n$-butanol (BuOH) has been selected as a blend component in diesel, and is used from $50-100 \%$. The blends then have a reactivity range similar to the refinery streams, so single-cylinder engine tests for their emission and efficiency performance can also be used to determine their applicable load range.

The current paper presents a summary of the performance of such BuOH-diesel blends with respect to emissions and efficiency in the Partially Premixed Combustion regime. Besides a presentation of the sensitivity to injection strategies, dilution levels and fuel pressure, emission performance is compared to upcoming legislated emission levels. The effect of the blend ratio on load ranges is shown and conventional diesel combustion benchmarks are used to show improvements in indicated efficiency.

Butanol-diesel blends are shown to be a viable approach to partially premixed combustion, with its high soot reduction potential and stable operation. EURO VI emission levels can therefore be achieved, with moderate or slightly increased fuel pressure. Combustion efficiency is shown to be very reasonable over the whole load range, similar to that of conventional diesel combustion. Combined with an improved thermal efficiency a moderate butanol-diesel blend is shown to have an average gross indicated efficiency of $50 \%$ over the whole load range.
\end{abstract}

CITATION: Leermakers, C., Bakker, P., Somers, L., de Goey, L. et al., "Butanol-Diesel Blends for Partially Premixed Combustion," SAE Int. J. Fuels Lubr. 6(1):2013, doi:10.4271/2013-01-1683.

\section{INTRODUCTION}

Diesel engines are known for their relatively high efficiency, but traditionally suffer from significant emission levels of both particulate matter (PM) and nitrogen oxides (NOx) [1]. Over the past decades, manufacturers have largely overcome these harmful emissions by introducing new technologies, e.g. high pressure fuel injection equipment [2] and advanced exhaust gas after treatment [ $\underline{3}]$. These have not only added significant extra costs to vehicles, but have also broken the trend of ever increasing engine efficiency [4].

Partially Premixed Combustion $[\underline{5}, \underline{6}, \underline{7}]$ has shown the potential of further increasing engines' efficiency, with emissions of NOx and soot below future emissions regulations, and acceptable acoustic noise. With conventional fuels, i.e. diesel [] or gasoline [9], several challenges exist, but relatively low-octane-number gasoline fuels [10] were shown to be very well suitable for this concept. The reactivity of the fuels was shown to be determining the possible load range, which at best ranges from idle to full load, without major modifications to the engine setup. Both the groups of Saudi Aramco [10] and Lund [11] have used refinery streams, upstream precursors of conventional gasoline.

Such refinery streams are, however, not expected to be commercially available on the short term. For certain applications, the use of conventional diesel blended with a promising second-generation biofuel of low-reactivity and relatively high-volatility could provide a viable approach. That is, if such a blend can give similar emission advantages as the earlier mentioned refinery streams, and has a suitable load range.

Furthermore, the bio-component could provide additional advantages, such as the soot-reducing effects of atomic oxygen and a further reduction in effective carbon dioxide emissions. For the present investigation, $n$-butanol $(\mathrm{BuOH})$ has been selected as a blend component. 
Butanol is thought to be an important future fuel component [12]. It has excellent properties for blending with gasoline (especially branched or t-butanol) [13]. Nevertheless, the more reactive isomer, $n$-butanol, could be suitable for PPC purposes. The high oxygen content of $21 \mathrm{wt}-$ $\%$ is likely to contribute to low soot emissions and its relatively high heat of vaporization $(\sim 52.3 \mathrm{~kJ} / \mathrm{mole})$ is beneficial for lowering in-cylinder temperatures [14].

Moreover, butanol is of particular interest since it can be derived from biomass [15], like ethanol. Furthermore, butanol is favorable over ethanol for several reasons. It has a higher energy density, is less hygroscopic than ethanol ${ }^{1}$ and is less corrosive to several metals and polymers. Existing infrastructure could thus be used for transportation. Moreover, the lubricity is sufficiently high.

Nevertheless, pure bio-butanol or high butanol content blends in a diesel engine have not been investigated yet. Biobutanol can be directly used as gasoline fuel and the possibility to blend it with diesel in significant amounts (up to $40 \%$ ) was shown in a recent publication by Istituto Motori [17].

In the present paper butanol fractions of 50 to $100 \%$ are used. The blends then have a reactivity range similar to the refinery streams which were mentioned before, so singlecylinder engine tests for their emission and efficiency performance can also be used to determine their applicable load range.

The current paper presents a summary of the performance of the $\mathrm{BuOH}$-diesel blends with respect to emissions and efficiency in the Partially Premixed Combustion regime. Besides a presentation of the sensitivity to injection strategies, dilution levels and fuel pressure, emission performance is compared to upcoming legislated emission levels. The effect of the blending ratio on load ranges is shown and conventional diesel combustion benchmarks are used to show improvements in indicated efficiency.

\section{EXPERIMENTAL SETUP}

\section{Experimental Apparatus}

For this investigation a six-cylinder DAF engine, referred to as CYCLOPS, is used. For more information on the setup the reader is referred to a detailed description [ [8], of which this subsection is a short summary. Prior to this measurement campaign, the engine has been overhauled with new pistons and liners.

The CYCLOPS is a dedicated engine test rig, see Table 1, based on a DAF XE $355 \mathrm{C}$ engine. The pistons are of a lowcompression XE390c version, which together with the thickest head gasket available $(1.45 \mathrm{~mm})$ yield a compression ratio of 15.7. Cylinders 4 through 6 of this inline 6 cylinder HDDI engine operate under the stock DAF engine control unit and together with an eddy-current dynamometer they are only used to control the crankshaft rotational speed of the test cylinder, i.e. cylinder 1. Apart from the mutual cam- and crankshaft and the lubrication and coolant circuits, this test cylinder operates autonomously from the propelling cylinders and uses stand-alone air, EGR and fuel circuits for maximum flexibility.

\section{Table 1. CYCLOPS test setup specifications}

\begin{tabular}{|l|l|}
\hline Base Engine & 6 cylinder HDDI diesel \\
\hline Cylinders & 1 Test cylinder \\
\hline Bore $[\mathrm{mm}]$ & 130 \\
\hline Stroke $[\mathrm{mm}]$ & 158 \\
\hline Compression ratio & 15.7 (original 17.0$)$ \\
\hline
\end{tabular}

Fed by an air compressor, the intake air pressure of the test cylinder can be boosted up to 5 bar. Non-firing cylinders 2 and 3 function as EGR pump cylinders (see Figure 1), the purpose of which is to generate adequate EGR flow, even at 5 bar charge pressure and recirculation levels in excess of $70 \%$. The EGR flow is cooled both up- and downstream of the pump cylinders. Several surge tanks, to dampen oscillations and to ensure adequate mixing of fresh air and EGR flows, and pressure relief valves, to guard for excessive pressure in the circuit, have been included in the design.

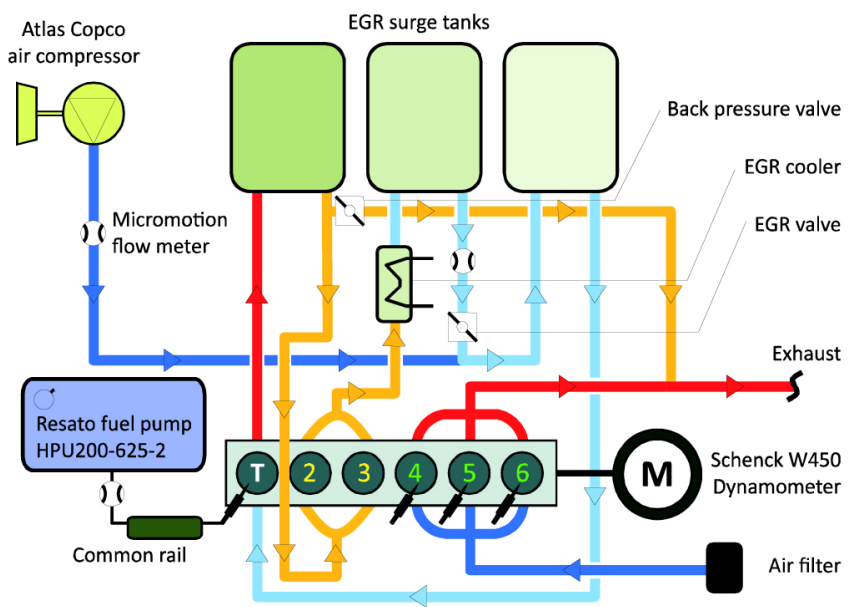

Figure 1. Schematic of CYCLOPS experimental setup: a modified DAF engine using separate fuel, air and EGR systems for one dedicated test cylinder

Direct injection of fuel into cylinder 1 is provided by a prototype Delphi common rail injector with a nozzle having 8 holes of $0.151 \mathrm{~mm}$ diameter with an umbrella angle of 153 degrees. All steady state flows of fuel, air and EGR are measured with Coriolis mass flow meters.

For measuring gaseous exhaust emissions, a Horiba Mexa 7100 DEGR emission measurement system is used. Exhaust smoke level (in Filter Smoke Number or FSN units) is measured using an AVL 415S smoke-meter. All quasi steady-

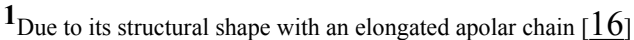


state engine data are recorded by means of an in house data acquisition system (TUeDACS). A SMETEC Combi crank angle resolved data acquisition system is used to record and process crank angle resolved data. For more information on the setup and the procedures and definitions used, the reader is referred to []].

\section{Fuel Blends Under Investigation}

Table 2 gives an overview of the specifications of the fuels which are used in the blends. $N$-butanol and EN590 diesel have both been tested according to ASTM D240 (higher heating value or HHV). To obtain the lower heating value or LHV the heat released by the condensing water has been subtracted from the higher heating value.

Table 2. Fuels used for the blends

\begin{tabular}{|l|l|l|l|l|l|}
\hline Fuel & CN & AFR & $\begin{array}{l}\mathrm{HHV} \\
{[\mathrm{MJ} / \mathrm{kg}]}\end{array}$ & $\begin{array}{l}\mathrm{LHV} \\
{[\mathrm{MJ} / \mathrm{kg}]}\end{array}$ & $\begin{array}{l}\text { Boiling } \\
\text { range } \\
{\left[{ }^{\circ} \mathrm{C}\right]}\end{array}$ \\
\hline$n$-butanol & $17[18]$ & 11.13 & 35.76 & 33.02 & 117 \\
\hline EN590 & 52.4 & 14.6 & 45.4 & 42.7 & $\begin{array}{l}170- \\
360\end{array}$ \\
\hline
\end{tabular}

The $n$-butanol has been tested for any unwanted impurities in a combined gas chromatography-mass spectrometer (GC-MS), type GCMS-QP5000 from Shimadzu. Di-ethyl ether (DEE) is used as a solvent, because of its high volatility and lower boiling point compared to the test substances.

Obtained GC spectra and full compositions are presented as appendices, see Figure 20 and Table 5. As can be seen, one major peak which saturated the detector was found. Apparently, the $n$-butanol consists of almost only 1-butanol and probably some 2-butanol. Those two molecules could not be distinguished with the current settings and column. Only a minor fraction of 2-pentanol $(0.13 \mathrm{wt}-\%)$ was found.

Five blends with relatively high butanol content (i.e. 90-80-70-60-50 vol-\%) have been investigated for this research. No visual separation in the diesel-butanol blends was found over a period of a number of weeks. Apart from varying reactivity and volatility, using different blend contents also implies varying air fuel ratios and heating values due to the relatively high differences in both AFR and heating value caused by the presence of oxygen in the molecule.

The fuel blends have not been tested on a CFR engine for octane number or on an ignition quality tester for cetane number. Therefore, only a rough estimation of the reactivity of each of the blends, based on linear blending, can be given. The reference $\mathrm{CN}$ value for $n$-butanol, being 17 , is taken from [19]. Some properties of the blends used, are given in Table 3.
Table 3. Specific parameters for the tested blends

\begin{tabular}{|l|l|l|l|}
\hline & AFR $_{\text {st }}[-]$ & LHV [MJ/kg] & Estimated CN [-] \\
\hline BuOH90 & 11.48 & 33.99 & 20.5 \\
\hline BuOH80 & 11.82 & 34.96 & 24 \\
\hline BuOH70 & 12.17 & 35.92 & 27.6 \\
\hline BuOH60 & 12.52 & 36.89 & 31.1 \\
\hline BuOH50 & 12.87 & 37.86 & 34.7 \\
\hline
\end{tabular}

\section{Conditions and Procedure}

Based on the results of Manente [20], the engine speed is set to $1250 \mathrm{rpm}$, which is typical for a heavy duty vehicle during highway cruising. An EGR flow of around 50 weight percent is used, both to limit pressure rise rates, as found in previous work [21] , and nitrogen oxides emissions to levels below Euro VI $[\underline{22}, \underline{23}]$.

The latter two references have stated that a combustion temperature higher than $1500 \mathrm{~K}$ is necessary to promote the reactions from $\mathrm{CO}$ to $\mathrm{CO}_{2}$, and that on the other hand it is important to be below $2000 \mathrm{~K}$ to avoid thermal NO formation (Zeldovich' mechanism). Apart from an EGR percentage of around $50 \mathrm{wt}-\%$, this also implies the use of a global lambda value of around 1.5. To achieve such an air excess ratio, intake pressure is varied accordingly.

The recirculated exhaust gas is heavily cooled using cold process water, to approximately $300 \mathrm{~K}$ and the exhaust back pressure is regulated to $0.3 \pm 0.2$ bar higher than the intake pressure (to mimic the presence of a turbocharger of finite efficiency and to enable the use of external short route EGR in practice). The 0.3 bar excess exhaust pressure is considered to be feasible with sufficient high turbocharger efficiency. The error interval given is caused by test bench limitations.

Summarized, for all measurements the following conditions are kept constant:

- Engine speed $=(1250 \pm 10) \mathrm{rpm}$

$\bullet \lambda=(1.5 \pm 0.1)$

- $(50 \pm 5) \mathrm{wt}-\%$ of EGR

At 8 bar gross IMEP, first the combustion behavior is tested for all blends, using a single injection strategy. After that, a double injection strategy is compared to the more conventional single injection, by varying the start of injection (SOI) until the desired CA50 is reached within $\pm 1{ }^{\circ} \mathrm{CA}$.

- Single injection - five SOIs aiming at CA50s of 2, 4, 6, 8, and $10^{\circ} \mathrm{CA}$ aTDC at 8 bar.

- Double injection strategy.

Furthermore, the sensitivity of combustion behavior with respect to the total dilution level will be analyzed, by increasing the intake pressure in 0.1 bar increments, keeping all other parameters constant. This results in:

- Air excess ratios ranging from 1.5 to 2.5, keeping EGR level and all other parameters constant. 
Particulate emission levels from conventional diesel combustion are known to be sensitive to the fuel pressure used. Whether this is still the case when using butanol-diesel blends is tested using a fuel pressure sweep. This results in:

- Fuel pressure varying from 1400 bar down to 800 bar, with 100 bar increments.

After these sensitivity analyses, the load range of each of the fuels will be shown, for which five loads have been selected. For each target load \pm 0.5 bar, the fuel mass flow is kept constant and small variations in load (originating for varying efficiencies) are allowed accordingly:

- Gross IMEPs of 8,10,12, 14 and 16 bar, corresponding to $32-64 \%$ of the engine's rated torque

Fuel pressure increases with load to keep injection duration roughly at a constant in crank angle domain. A moderate 1000 bar at 8 bar load is taken as starting point and with every 2 bar of load increase, fuel pressure will be increased with 200 bar.

All operating points should have acceptable combustion stability (i.e. $\sigma_{\mathrm{IMEP}}<5 \%$ ) and preferably meet each of the following emission levels:

- $\mathrm{CO}$ emissions below $2000 \mathrm{ppm}$,

- UHC emissions below 1000 ppmC with as target below 400 ppmC,

- NOx emissions below 200 ppm with as a target below 50 ppm to reach EURO VI,

- FSN smoke number below 1 with as a target below 0.2 to reach EURO VI.

As a consequence of the exotic operating conditions, hardware and setup limitations should be kept in mind.

- Originally, this engine has been designed for peak firing pressures of 225 bar. This limit has been lowered to 200 bar due to the highly asymmetric load on the crank shaft.

- Pressure rise rates (PRR) should not exceed a certain limit to prevent engine damage and excessive combustion noise. According to Leermakers [ $\underline{8}]$, this setup has proven to work with pressure rise rates of $30 \mathrm{bar} /{ }^{\circ} \mathrm{CA}$. Nevertheless, it is wise to lower this limit somewhat $\left(15 \mathrm{bar} /{ }^{\circ} \mathrm{CA}\right)$.

-Wall wetting could lead to liner damage by means of oil dilution. As an indicator for this, the $\mathrm{HC}$ emissions have been limited to $2000 \mathrm{ppmC}$.

\section{Definitions}

The calculated crank angle at which $10 \%$ of the fuel has been burnt as main indicator for the start of combustion (SOC). This is used to compute relevant combustion properties such as ignition delay, ignition dwell, combustion delay and combustion duration. Moreover, the duration between end of injection and start of combustion is also defined. This so-called ignition dwell, if positive, is beneficial for reduced soot production, i.e. injection has ended before combustion starts. These parameters can be summarized as:

- Ignition delay (ID) is defined as $\mathrm{CA} 10$ - $\mathrm{SOI}_{\text {main }}$

- Burn duration (BD) is defined as CA90 - CA10

- Ignition dwell is defined as CA10 - $\mathrm{EOI}_{\text {main }}$

\section{Premixed fraction}

It has been postulated before that Partially Premixed Combustion can vary in the amount of premixed combustion. This is quantified by comparing the heat released in the premixed combustion phase and the total heat released. The premixed fraction is defined using the method suggested by Solaka and coworkers [24] is followed, where a Gaussian profile is fitted to the rising flank of the premixed peak, between half of the maximum and the actual peak. The Gaussian profile is defined as

$$
G(x)=h \cdot e^{-\left(\frac{x-x_{0}}{2 \alpha^{2}}\right)^{2}}
$$

with $\mathrm{x}_{0}$ the central position of the peak, and $\mathrm{h}$ and $\alpha$ representing the height and width of the Gaussian profile, respectively. From Figure 2 can be seen that the fit follows the premixed heat release closely. The Gaussian profile is merely a mathematical representation of the premixed reaction phase. However, it shows a robust measure of the premixed fraction for all operated cases.

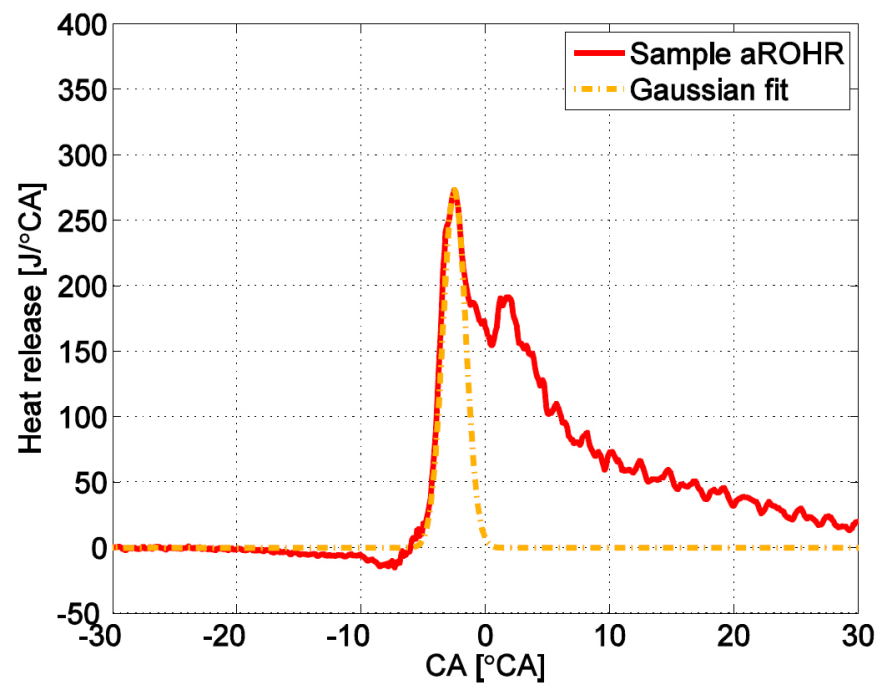

Figure 2. Rate of Heat Release and Gaussian profile as a function of crank angle degree. Gaussian fit is used to define the premixed fraction

\section{Efficiencies}

Combustion efficiency provides information about the completeness of combustion and it is used to derive thermal efficiency. In order to calculate the combustion efficiency all 
specific emissions (i.e. ISCO, ISHC, ISPM and ISH2) should be known. However, soot (ISPM) is often considered to be negligible for combustion efficiency since the specific emissions are low and does not contain a lot of energy. The combustion efficiency is calculated according to:

$$
\eta_{\text {comb }}=\frac{I S C O \cdot L H V_{C O}+I S H C \cdot L H V_{H C}+I S H 2 \cdot L H V_{H 2}}{I S F C \cdot L H V_{f u e l}} .
$$

Gross indicated $\left(\eta_{\text {ind }}\right)$ will be calculated according to:

$$
\eta_{\text {ind }}=\frac{P_{\text {ind }}}{\dot{m}_{\text {fuel }} Q_{L H V}},
$$

$P_{\text {ind }}$ is based on the work done in the compression and expansion stroke, $Q_{L H V}$ represents the lower heating value of the fuel and $\dot{m}_{f u e l}$ is the fuel flow rate. Once gross indicated efficiency (based on pressure trace) and combustion efficiency (based on both pressure trace and emission level) are known, one can calculate the thermal efficiency:

$$
\eta_{\text {th }}=\frac{\eta_{\text {ind }}}{\eta_{\text {combustion }}} .
$$

\section{RESULTS AND DISCUSSION}

During initial tests, it has been found to be hardly possible to operate pure $n$-butanol at moderate loads, low intake temperature, and the present compression ratio. Therefore, only blends of butanol and diesel are considered in the following sections. Where applicable these blends are also compared to pure diesel.

\section{Blending Ratio and Combustion Phasing}

Combustion characteristics (i.e. heat release patterns and emissions) will greatly depend on the content of the blend, through a different volatility and reactivity. Therefore, in the following subsections, heat release, controllability and emissions are investigated for one target load (i.e. 8 bar gross IMEP), 50 wt-\% EGR, an air excess ratio of 2, and four butanol-diesel blends.

\section{Heat release pattern}

Increasing the diesel content of the blend is expected to gradually smoothen the combustion. Therefore, a blending ratio sweep has been performed using a single injection and $50 \mathrm{wt} \%$ EGR. For a fixed combustion phasing (CA50), Figure 3 reveals the expected decrease in maximum heat release rate with increasing diesel content.

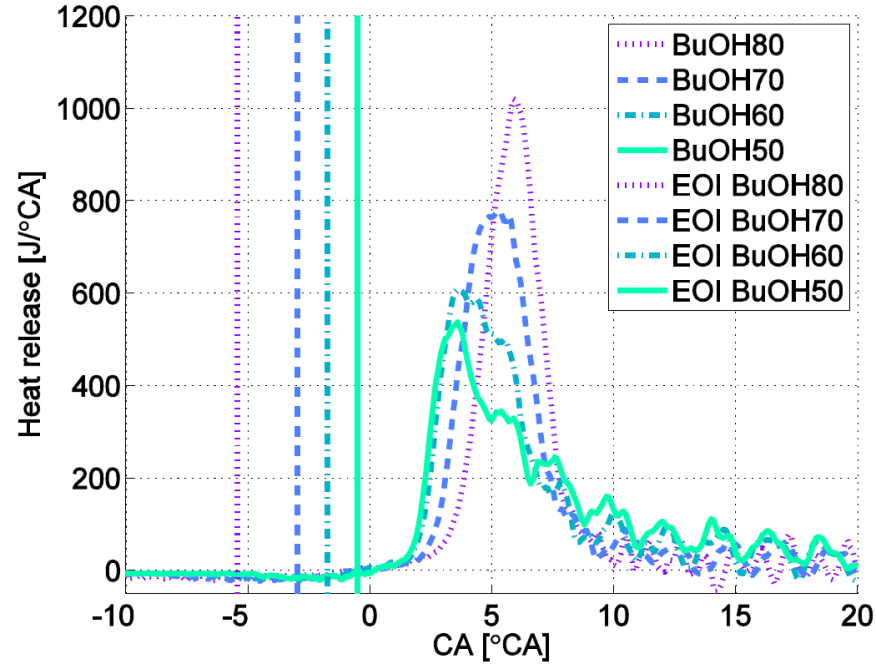

Figure 3. Heat release for various fuel blends and CA50 $=6 \operatorname{deg} C A$ aTDC

Through the added diesel, the ignition delay is somewhat shortened and heat release shows more of a mixing-controlled phase, instead of just a premixed peak.

This intended effect of adding diesel, i.e. increasing the burn duration can also be seen in Figure 4. Engine lifetime can be ensured by keeping burn durations and consequently maximum pressure rise rates below a certain threshold. In fact this is why earlier combustion phasings for $\mathrm{BuOH} 80$ are not taken into account. Advancing combustion earlier than 6 ${ }^{\circ} \mathrm{CA}$ aTDC would violate pressure rise rate limits, as may already be expected from the burn duration of only $3{ }^{\circ} \mathrm{CA}$ at $6{ }^{\circ} \mathrm{CA}$ aTDC.

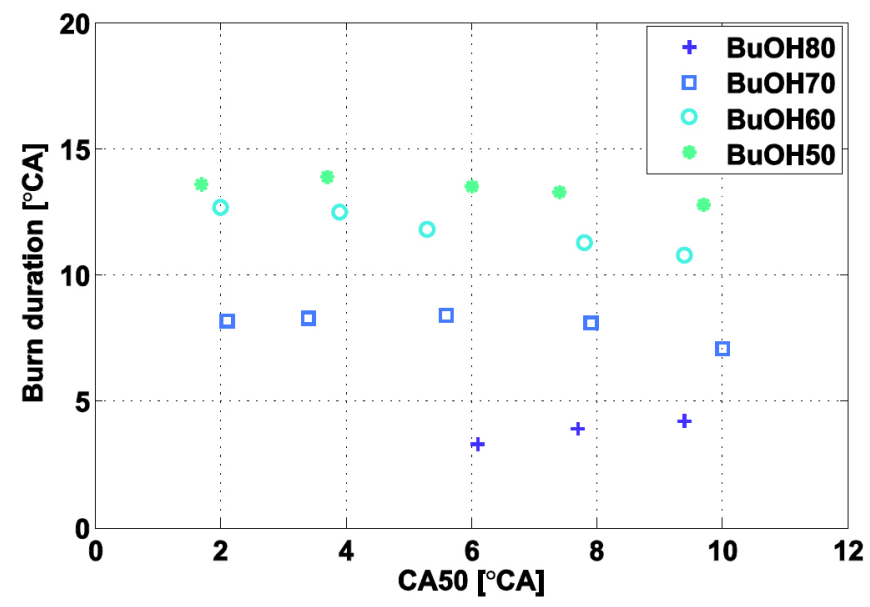

Figure 4. Burn durations for various fuel blends and varying combustion phasing.

For the less reactive $\mathrm{BuOH} 70$ through $\mathrm{BuOH} 50$, timing can be advanced arbitrarily. 


\section{Controllability and stability}

One of the challenges of (Partially) Premixed Combustion can be (a lack of) controllability. In another paper by the authors [25] it was proposed to use the sensitivity of the ignition delay $\left(S_{I D}\right)$ as means to quantify the controllability, i.e. the derivative of CA50 with respect to a change in injection timing:

$$
S_{I D}=\frac{\partial C A 50}{\partial S O I}
$$

At very early injection timings, where ignition is dominated by global parameters, the response of injection timing is very low, i.e. $S_{I D} \ll 1$. On the other hand, with very low-reactive fuels and late injection timings, a small change in injection timing can lead to a big change in combustion phasing, or even misfiring. As such, $S_{I D}$ can also be much larger than one. For good controllability a value near unity, as experienced for conventional diesel combustion, is desired.

This $S_{I D}$ could also be used for less reactive fuels as an indicator for practical implementation. Figure 5 depicts the sensitivity for the $50,60,70$ and $80 \%$ butanol blends at an air excess ratio of 2 and 8 bar gross IMEP. As can be seen from this figure, $\mathrm{BuOH} 50$ and BuOH60 approach $S_{I D}=1$.

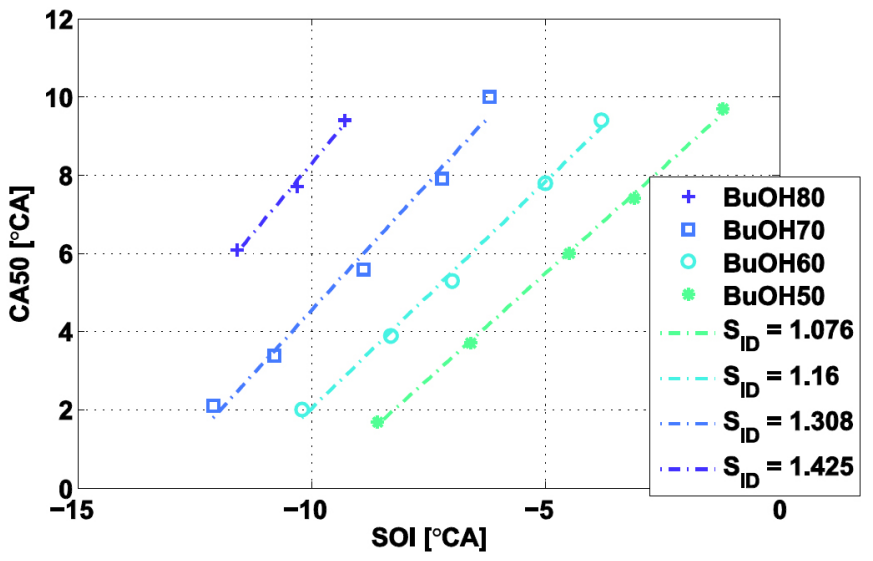

Figure 5. Combustion phasing response varying the injection timing for four butanol-diesel blends.

The BuOH80 blend, however, has a larger value for $S_{I D}$ and is significantly less stable. This effect is experienced even more for the pure butanol, or $\mathrm{BuOH} 100$, for which combustion was too unstable to be included in these results, with high cycle-to-cycle variability and an associated compromised combustion efficiency.

\section{Emissions}

For the premixed combustion of pure $n$-butanol, low emission levels are expected. Especially with respect to particulate matter emissions, the atomic oxygen is expected to reduce this. However, this might a second order effect in the PPC regime. If that is not the case by adding diesel, this might give rise to only a small increase in soot levels proportional to the diesel content as long as the whole charge burns in more or less premixed mode.

The emissions for varying combustion phasing and diesel content are shown in Figure 6. First of all, nitrogen oxides levels seem to be mainly dominated by the ambient conditions (i.e. EGR levels, intake temperature, air excess ratio) and combustion phasing. An earlier combustion phasing leads to higher peak temperatures and longer residence times at such temperatures which both increase thermal NO formation.
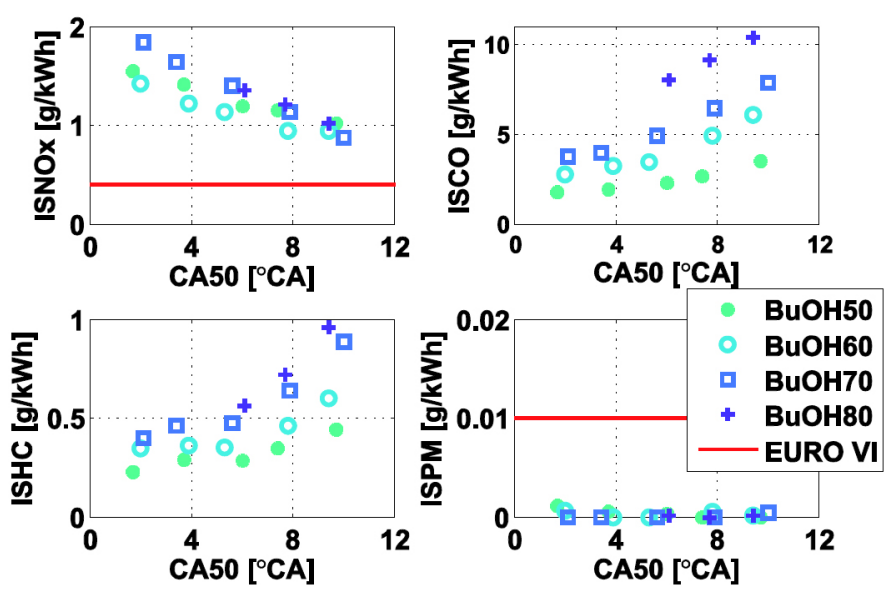

Figure 6. Overview of emission for various fuel blends at 8 bar IMEP with 50\% of EGR and a fuel pressure of 1500 bar.

Unburned hydrocarbon en $\mathrm{CO}$ emissions do show a trend with the diesel content of the blends. Apparently, for a given CA50 the decreasing volatility and the later injection timing results in higher local equivalence ratios and combustion temperatures which results in lower $\mathrm{CO}$ and $\mathrm{HC}$ emissions. Furthermore, later combustion phasing, with reduced global combustion temperatures, gives rise to incomplete oxidation of the fuel as to be expected.

Regardless of the blending content, minimal to near-zero soot is formed for any combustion phasing. The atomic oxygen, as well as the highly premixed combustion mode as shown in Figure 3 contribute in near-zero smoke levels. Tests at higher loads might show which of these effects is more dominant.

\section{Multiple Injections}

The use of a multiple injection strategy is known for its reduction potential of noise and possibly NOx emissions. Using diesel fuel, late cycle pilot injections are relatively hard to use, because the fuel is too reactive and will start to burn before top dead center, which can be detrimental for efficiency.

Butanol blends, because of the lower reactivity, are expected to be much more suitable for such late pilot injections. The use of these multiple injection is useful for decreasing local equivalence ratios and therewith peak temperatures. A decrease in nitrogen oxide emissions is 
expected without too much of a penalty in either $\mathrm{HC}$ or $\mathrm{CO}$ emissions as global temperatures remain at similar levels.

Furthermore these pilot injections can be useful for shaping the heat release to the desired pattern, and as such efficiency can benefit from this strategy. Most important, however, the pilot injections can be used to control excessive pressure rise rates, yielding noise reductions. This effect on the heat release rate is shown in Figure 7, where also the injector actuation signals are denoted.

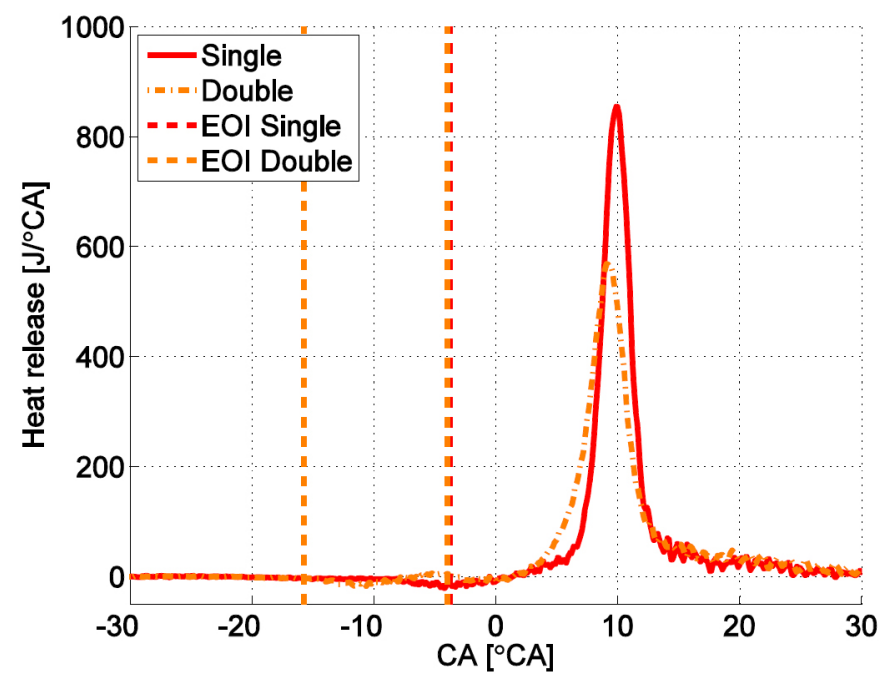

Figure 7. Heat release and injector actuation profile comparing single and double injections of BuOH6O. (Note that the end of the second injection in the double strategy nearly coincides with the end of the single injection.)

From Table 4 also the other effects from this double injection strategy can be seen. Indeed, the maximum pressure rise rate and NOx levels are reduced, but there is a slight penalty in combustion efficiency. Additional fine-tuning and rate shaping of the multiple injections could improve the efficiency. Still a single injection with sufficient ignition delay is good enough for partially premixed combustion at moderate to high loads so it might not be worth the effort.

Table 4. Engine parameters and results during BuOH6O injection strategy comparison

\begin{tabular}{|l|l|l|l|}
\hline & & Single & Double \\
\hline IMEPgross & {$[$ bar $]$} & 7.7 & 7.4 \\
\hline CA50 & {$\left[{ }^{\circ} \mathrm{CA}\right.$ aTDC $]$} & 10.2 & 9.8 \\
\hline SOIpilot & {$\left[{ }^{\circ} \mathrm{CA}\right.$ aTDC $]$} & & -14.3 \\
\hline SOImain & {$\left[{ }^{\circ} \mathrm{CA}\right.$ aTDC $]$} & -7.9 & -3.4 \\
\hline MPRR & {$\left[\mathrm{bar} /{ }^{\circ} \mathrm{CA}\right]$} & 11.5 & 7.9 \\
\hline$\lambda$ & {$[-]$} & 1.50 & 1.53 \\
\hline$\eta_{\text {ind }}$ & {$[-]$} & 0.483 & 0.476 \\
\hline$\eta_{\text {comb }}$ & {$[-]$} & 0.989 & 0.981 \\
\hline ISNOx & {$[\mathrm{g} / \mathrm{kWh}]$} & 0.57 & 0.37 \\
\hline ISPM & {$[\mathrm{g} / \mathrm{kWh}]$} & 0.001 & 0.0002 \\
\hline
\end{tabular}

\section{Total Dilution Effect}

It is generally known that increasing the total dilution, i.e. the total amount of fresh air and EGR, divided by the stoichiometric amount of air necessary for a certain amount of fuel, increases an engine's efficiency. This fact occurs through a more ideal thermodynamic cycle, i.e. the ratio of specific heats does not change too much between compression and expansion, but even more importantly to the lower amount of heat loss to the cylinder walls.

This observation implies that maximizing the total dilution will contribute to maximizing efficiency. However, it should be emphasized that for practical implementations, boost pressure cannot be increased infinitely. In particular high amounts of EGR can decrease the maximum boost pressure since using EGR reduces the available exhaust enthalpy that drives the exhaust turbine. Still the effect of this total dilution will be investigated.

One total dilution sweep has been performed with BuOH60. Limited by the setup's maximum exhaust back pressure, the highest air excess ratio was around 2.5, while still using $50 \mathrm{wt}-\%$ of EGR and the aforementioned pressure difference between intake and exhaust (i.e. -0.3 bar). The amount of injected fuel was kept at a constant 1.0 gram per second, whereas injection timing was adjusted to obtain a target CA50 of $7.5 \pm 0.5^{\circ} \mathrm{CA}$ aTDC.

Starting from an air excess ratio of 1.5 , intake pressure was increased in 0.1 bar increments, while the EGR rate was adjusted to be near the 50 wt- $\%$ target. Figure 8 shows the gross indicated efficiencies for changing total dilution rates. This gross indicated efficiency increases by more than $10 \%$ (4\% point) going from an air excess ratio of 1.5 to 2.5

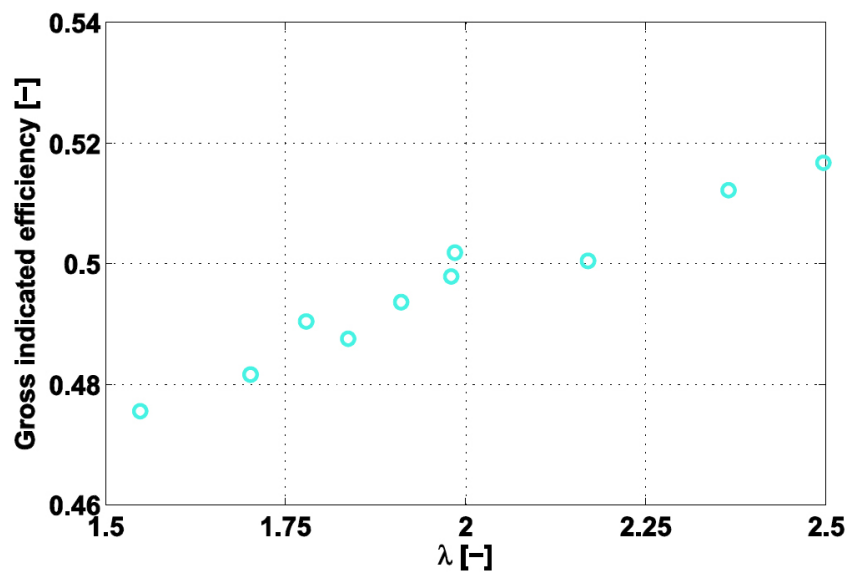

Figure 8. Gross indicated efficiency as a function of lambda, at 50 m\% EGR.

Emissions levels, as shown in Figure 9, show the expected trends except for nitrogen oxides. NOx levels are expected to decrease with increasing total dilution due to the increased heat capacity. However, this is likely counterbalanced by a reduced spray penetration and increased local equivalence ratios, i.e. higher local temperatures increase NO formation 
Both $\mathrm{HC}$ and $\mathrm{CO}$ emissions are hypothesized to decrease as a result of increased in-cylinder density at time of injection. This would affect spray penetration and results in less fuel near the cylinder wall. Like for the NOx emissions, testing this hypothesis requires further investigations, preferably in an optically accessible engine. Finally, particulate matter emissions are close to zero caused by the mechanisms described before.
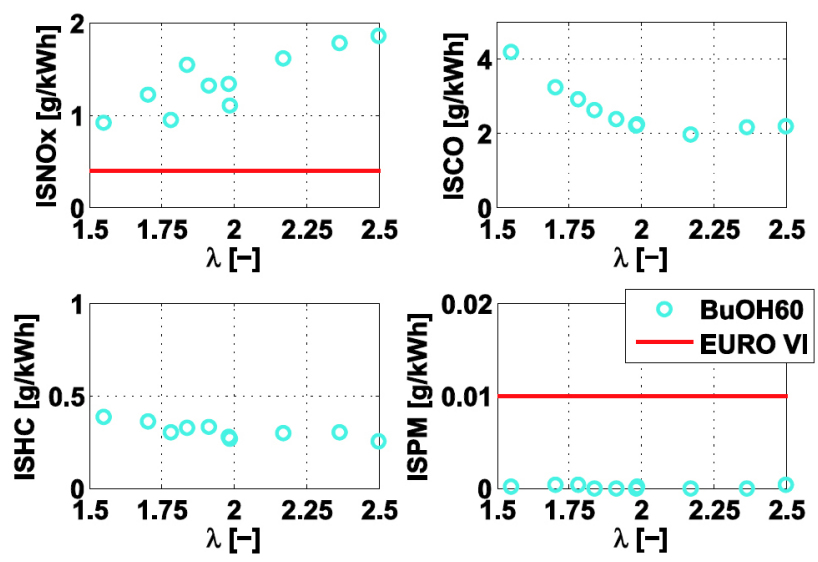

Figure 9. Observed emission trends as a function of varying total dilution rates.

\section{Fuel Pressure Sensitivity}

Conventional diesel combustion, with conventional diesel fuels is known to be sensitive to the fuel pressure used. As can be seen from Figure 10, where smoke emissions are shown as a function of the fuel pressure with all other parameters kept constant (Table 5), for the EN590 diesel fuel the emission of particulate emissions significantly decreases as fuel pressure is increased.

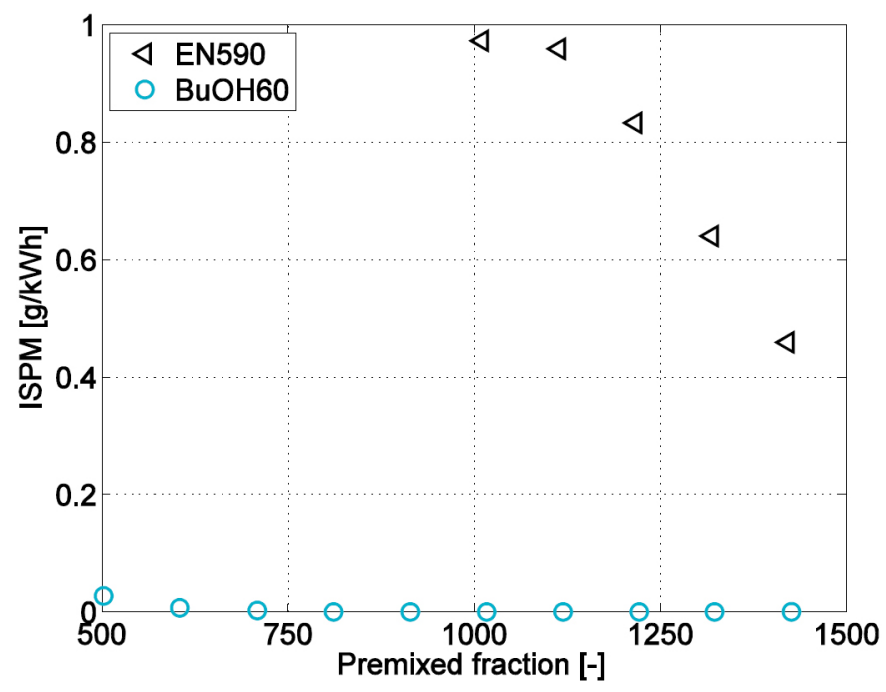

Figure 10. Particulates emissions as a function of fuel pressure
Table 5. Engine parameters during fuel pressure variation

\begin{tabular}{|l|l|l|}
\hline IMEPgross & {$[\mathrm{bar}]$} & $7.8 \pm 0.2$ \\
\hline CA50 & {$\left[{ }^{\circ} \mathrm{CA}\right.$ aTDC $]$} & $4.0 \pm 0.3$ \\
\hline EGR & {$[\mathrm{wt}-\%]$} & $50 \pm 5$ \\
\hline$\lambda$ & {$[-]$} & $1.5 \pm 0.1$ \\
\hline $\mathrm{n}$ & {$[\mathrm{rpm}]$} & $1250 \pm 10$ \\
\hline
\end{tabular}

Therefore, if low soot emissions are requested, the diesel injection pressure should be set to a high enough value, therewith increasing parasitic losses. For the $\mathrm{BuOH} 60$, however, at least for the load under investigation (i.e. 8 bar IMEP), no significant increase in PM emissions is seen for decreasing fuel pressure. As far as smoke levels go, a reduction of this fuel pressure is allowed.

The low sooting tendency of the BuOH60 can be explained using Figure 11, where the premixed fraction of combustion is computed for all fuel pressures and fuels. For $\mathrm{BuOH} 60$, independent of fuel pressure, the major part of the fuel combusts in the premixed heat release peak. For diesel, even at the highest fuel pressure the amount of premixed combustion is relatively low. The combined effect of mixing controlled combustion and the composition of diesel fuel results in high PM emissions.

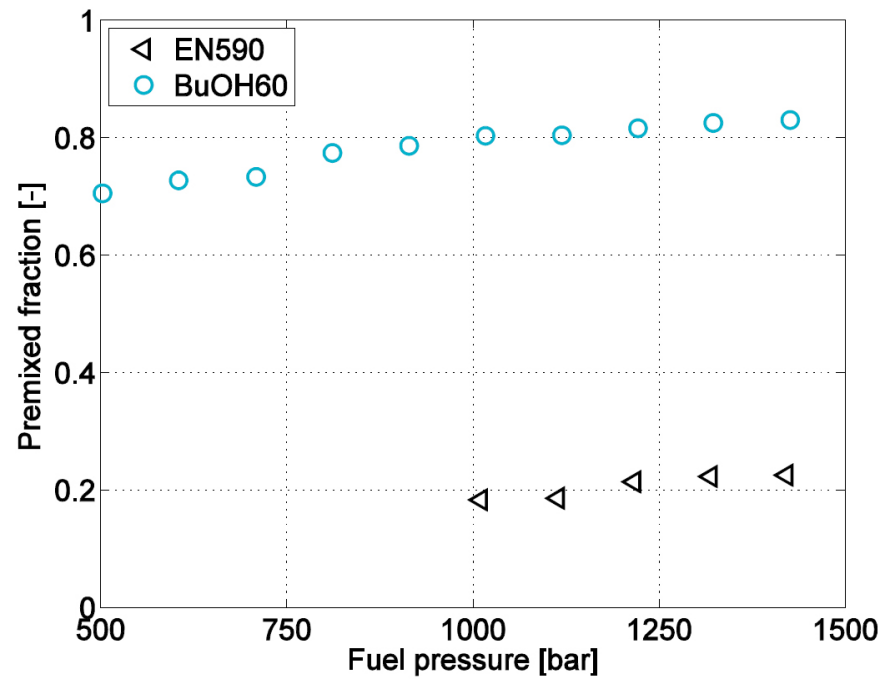

Figure 11. Premixed fraction of the heat release as a function of fuel pressure

This effect can be illustrated even more clearly if the particulate emissions are plotted as a function of this premixed fraction, as can be seen in Figure 12. In this graph, also three naphtha blends from another study [26] of medium reactivity are represented, which helps to illustrate the clear trend of decreasing smoke levels with the premixed fraction. 


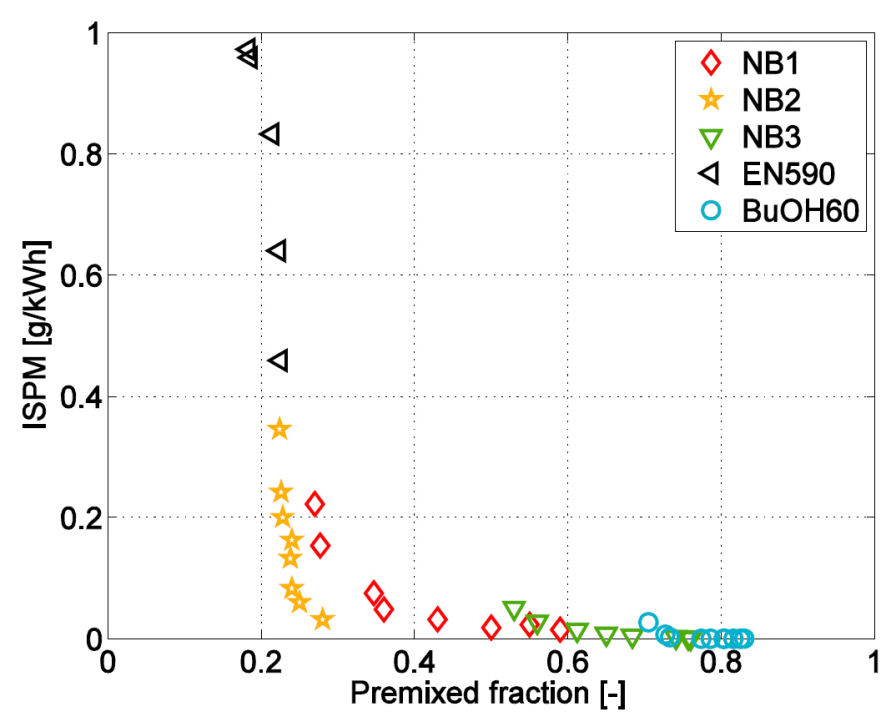

Figure 12. Particulates emissions as a function of the premixed fraction, for diesel, $\mathrm{BuOH6O}$ and three medium-reactivity naphtha blends

\section{Load Variation}

Building on the sensitivity studies of the former sections, all fuels have been tested over the selected load range using a single injection and a target CA50 of $8 \pm 1{ }^{\circ} \mathrm{CA}$ aTDC. Injection timings have been adjusted to keep this combustion phasing constant. Over the load range, air-excess ratio and EGR fraction have been kept constant, intake pressure follows from this. Exhaust back pressure is kept at a constant margin over the intake pressure (to mimic a turbo charger with finite efficiency, and to be able to use external short route EGR in practice). Where applicable, the butanol-diesel blends are also compared to diesel, under the same conditions.

\section{Heat release patterns}

Figure 13 shows heat release patterns for five different butanol-diesel blends at 12 bar gross IMEP. At this load, differences between the blends are larger than was previously seen in Figure 3 for 8 bar IMEP.

The lowest reactivity blends now (at 12 bar) show more mixing-controlled heat release patterns, similar to that of conventional diesel combustion (shown in black). Only the $\mathrm{BuOH} 90$ blend is still mainly premixed.

For one blend in particular, i.e. the $60 \% n$-butanol - diesel blend (see Figure 14), a clear transition to mixing controlled combustion is observed when the load is increased from 8 to 16 bar gross IMEP.

In order to quantify the grade of premixing during this transition, again the premixed portion of the heat release is computed for every fuel-load combination (see Figure 15). As can be seen from this graph, for all blends the premixed fraction decreases with load.
For the lowest butanol contents (i.e. $\mathrm{BuOH} 50$ and 60), the premixed fraction saturates at roughly $25 \%$. Above this load, no further decrease is observed due to a near constant ignition delay (not shown here). As the injection duration is kept roughly constant in the crank angle domain, the fraction of fuel injected during the constant ignition delay also remains constant. Up to this saturation load, however, clear differences can be distinguished between the blends. For pure diesel this premixed saturation occurs already at much lower loads, and over the load range under investigation, the premixed fraction is nearly constant.

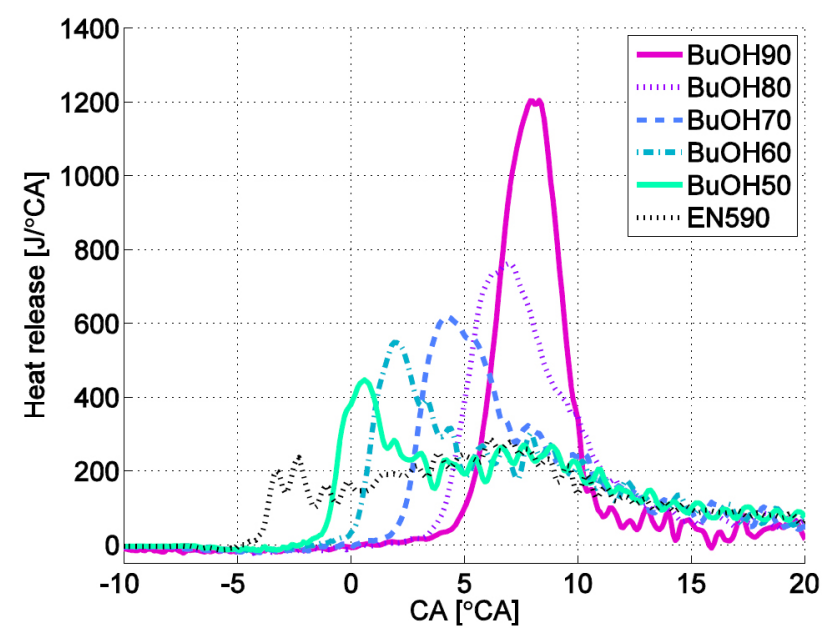

Figure 13. Heat release at 12 bar gross IMEP, 1400 bar fuel pressure. $\mathrm{CA50}=8^{\circ} \mathrm{CA}$ aTDC

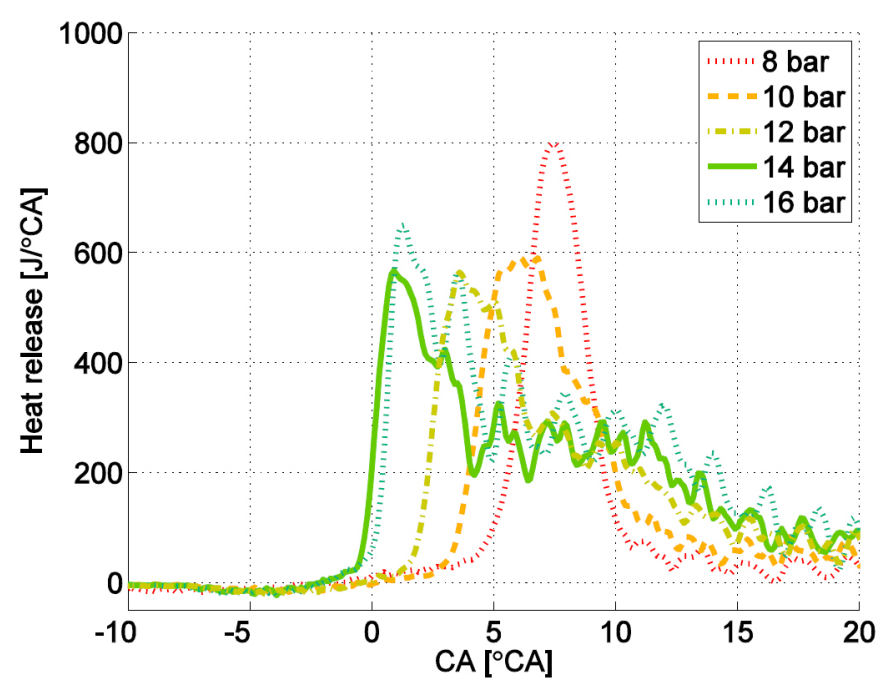

Figure 14. Heat release patterns for a load sweep of BuOH60, with CA50 $=8^{\circ} \mathrm{CA}$ aTDC. 


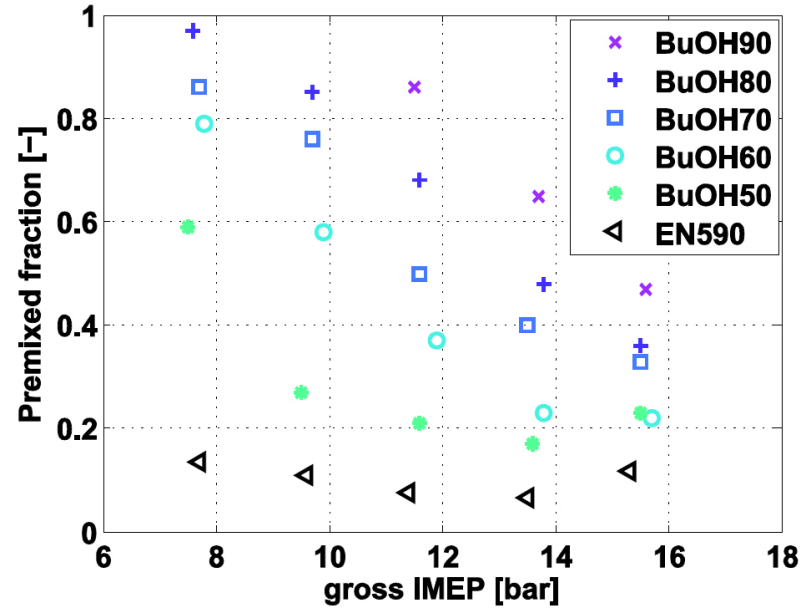

Figure 15. Premixed fraction as a function of load for all n-butanol-diesel blends, as well as pure diesel.

Traditionally, instead of the premixed fraction of combustion, the separation between the injection and combustion events has been used as a measure for the grade of premixing of fuel and air. As soon as this so-called dwell time becomes negative, soot formation is expected to occur. From Figure 16, it can be seen that the dwell time becomes zero at roughly 10 bar gross IMEP for BuOH50 and at 14 bar for $\mathrm{BuOH} 90$.

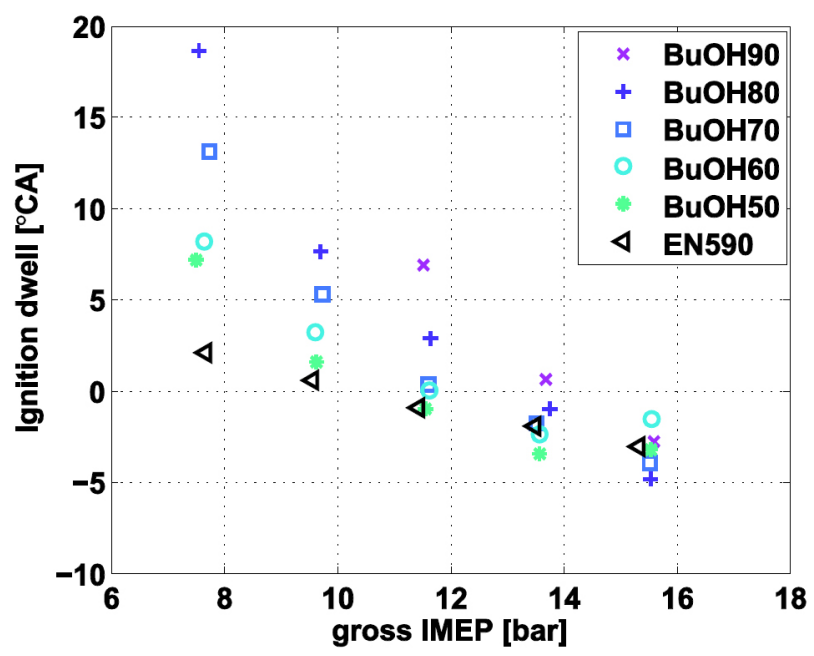

Figure 16. Ignition dwell as a function of load.

At relatively low loads, significant differences in dwell time can be distinguished between the fuels. However, as load increases these differences become smaller and smaller, and for higher loads even for the lowest reactivity $\mathrm{BuOH} 90$ blend, dwell times become similar to those of diesel.

Furthermore, high butanol content blends, together with PPC-like conditions, might result in quite aggressive combustion. Burn durations, which can give an indication of the maximum pressure rise rates or noise, are shown in Figure 17.

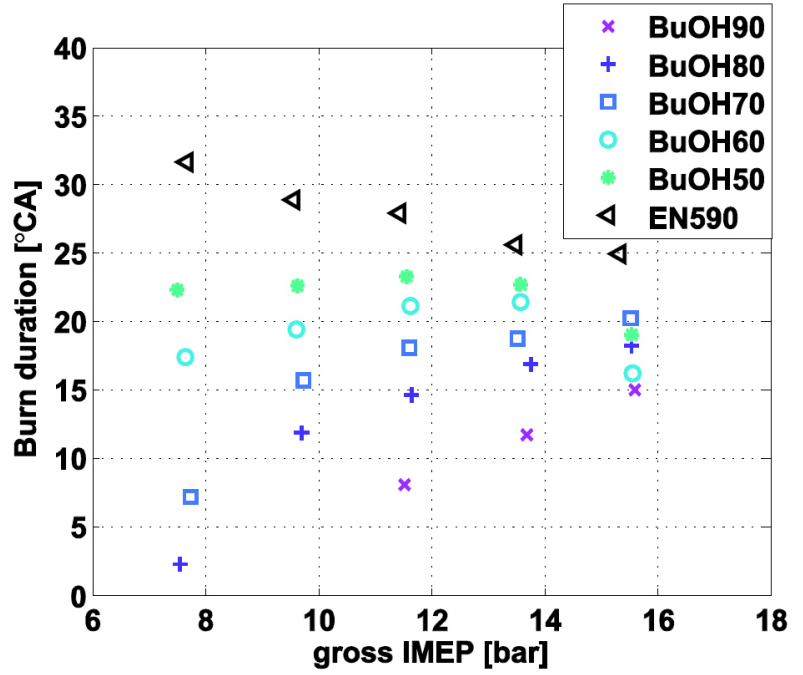

Figure 17. Burn duration as a function of load for all butanol blends and pure diesel

This graph indicates that blending with a second fuel of low reactivity is necessary to slow down combustion of purebutanol somewhat, especially at lower loads. For such low loads (i.e. 8 bar IMEP), $70 \% n$-butanol is the maximum blending ratio for practical implementations, given the aforementioned hardware limits. At higher loads, as the amount of premixed burn becomes lower in absolute value, and the same for all blends, burn duration becomes both sufficiently long and approaches a common value for all blends. However, all butanol-diesel blends have shorter burn durations than diesel only, which leads to a higher potential efficiency.

\section{Emissions}

The major benefit of using the butanol-diesel blends in partially premixed combustion is the soot reduction potential, as can be seen from Figure 18. For all the butanol blends, PM emissions are near or below the EURO VI legislated levels. Furthermore, they are up to two orders of magnitude lower than for the EN590 diesel fuel (for which levels have been divided by 10 for clarity). The blends with moderate amounts of butanol can reach the EURO VI levels, even with moderate fuel pressures (compared to currently available engines). This reduction in fuel pressure can help in increasing brake efficiency, as parasitic losses are somewhat limited.

For nitrogen oxides emissions, no clear trends can be seen between the blends and diesel. These NOx levels are in this case dominated by the ambient conditions, as the dilution level effectively suppresses the NOx emissions to near or below EURO VI levels. For butanol-diesel points not fully EURO VI compliant, a somewhat higher EGR percentage could be a solution and the penalty in PM might either be acceptable, or can be reduced with a slightly increased fuel pressure. 

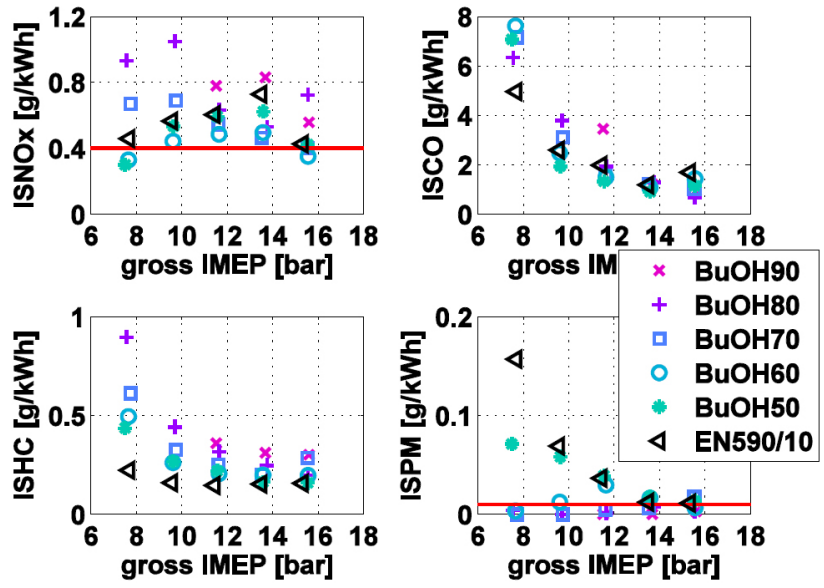

Figure 18. Emission levels as a function of load for all butanol blends and pure diesel. Note that for diesel, PM emission levels are divided by 10 for clarity.

For carbon monoxide, all butanol blends perform just as well as diesel, with fully acceptable levels at increased loads. Unburned hydrocarbons, however, are somewhat increased when more butanol is used in the blends. Absolute levels of these UHC emissions are within acceptable limits.

\section{Efficiency}

Apart from the significant emission reduction, partially premixed combustion holds the promise of optimizing an engine's efficiency, through shaping heat release to a thermodynamic optimum. The gross indicated efficiency for all blends is compared to that of regular diesel in Figure 19. As can be expected, for all fuels the relative percentage of heat loss reduces with increasing load, contributing to higher efficiency.

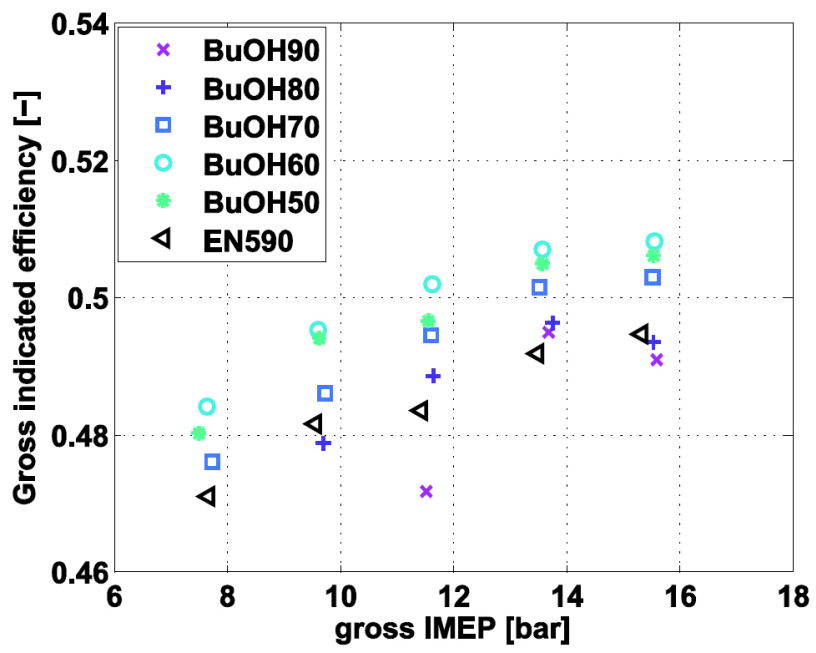

Figure 19. Gross indicated efficiencies as a function of load for all butanol blends and pure diesel.

The high butanol content blend, i.e. BuOH90, shows undesired combustion behavior at loads below 14 bar, with very short burn durations and relatively high $\mathrm{CO}$ and $\mathrm{HC}$ emissions and therefore its efficiency advantage is limited. Moderate blends (i.e. $\mathrm{BuOH} 70$ through $\mathrm{BuOH} 50$ ), however, show significant advantages, with $\mathrm{BuOH} 50$ showing an average $50 \%$ gross indicated efficiency over the load range.

If possible, by having high efficiency turbocharging and possibly long route EGR, an increase in air excess ratio could further reduce heat losses and therewith further increase efficiency. Through the total dilution mechanism shown before, and the results of this section, the authors have identified the path forward for achieving a $55 \%$ peak gross indicated efficiency, which will be fully investigated in future work.

\section{CONCLUSIONS}

From this research it can be concluded that moderate diesel-butanol blends (i.e. with 50,60 or $70 \%$ butanol in diesel) is a viable approach to partially premixed combustion, with the added diesel increasing burn durations to acceptable values, and enabling stable operation.

All such butanol-diesel blends have shown an extremely high soot reduction potential compared to diesel-only, even at moderate fuel pressures easily achieving EURO VI PM levels. At higher loads, all blends show a transition to more mixing-controlled combustion and the load at which this transition occurs depends on reactivity. For the butanol blends, this transition comes without a significant soot penalty.

Given the conditions used, NOx levels were not all EURO VI compliant, but the EGR levels can be somewhat increased and the PM penalty is either acceptable or can be diminished with a slight increase in fuel pressure. These operational conditions also were shown to give very reasonable combustion efficiency (derived from $\mathrm{HC}$ and $\mathrm{CO}$ emissions) over the whole load range, similar to conventional diesel combustion.

Moderate blends were shown to give the best indicated efficiency over whole load range; with BuOH50 having an average gross indicated efficiency of $50 \%$ over the whole load range. If possible with high efficiency turbochargers, using a higher total dilution a pathway to even higher indicated efficiencies has been identified, with peak efficiency estimated at $55 \%$.

\section{REFERENCES}

1. Walsh, M., "Global Trends In Diesel Emissions Control - A 1998 Update," SAE Technical Paper 980186, 1998, doi: 10.4271/980186.

2. Mahr, B., "Future and Potential of Diesel Injection Systems," THIESEL 2002 Conference on Thermo- and Fluid-Dynamic Processes in Diesel Engines, Valencia (Spain), September 11th-13th, 2002.

3. Koltsakis, G., and Stamatelos, A., "Catalytic automotive exhaust aftertreatment," Progress in Energy and Combustion Science, 23(1): 1-39, 1997, doi: 10.1016/S0360-1285(97)00003-8.

4. Johnson, T., "Diesel Emission Control in Review," SAE Int. J. Fuels Lubr. 1(1):68-81, 2009, doi: 10.4271/2008-01-0069.

5. Noehre, C., Andersson, M., Johansson, B., and Hultqvist, A. "Characterization of Partially Premixed Combustion," SAE Technical Paper 2006-01-3412, 2006, doi: 10.4271/2006-01-3412.

6. Dec, J., "Advanced compression-ignition engines - understanding the incylinder processes," Proceedings of the Combustion Institute, 32(2): 2727-2742, 2009, doi: 10.1016/i.proci.2008.08.008. 
7. Kalghatgi, G., Risberg, P., and Ångström, H., "Partially Pre-Mixed Auto-Ignition of Gasoline to Attain Low Smoke and Low NOx at High Load in a Compression Ignition Engine and Comparison with a Diesel Fuel," SAE Technical Paper 2007-01-0006, 2007, doi: 10.4271/2007-01-0006.

8. Leermakers, C., Luijten, C., Somers, L., Kalghatgi, G. et al., "Experimental Study of Fuel Composition Impact on PCCI Combustion in a Heavy-Duty Diesel Engine," SAE Technical Paper 2011-01-1351, 2011, doi: $10.4271 / 2011-01-1351$.

9. Manente, V., Johansson, B, and Tunestal, P., "Partially Premixed Combustion at High Load using Gasoline and Ethanol, a Comparison with Diesel," SAE Technical Paper 2009-01-0944, 2009, doi: 10.4271/2009-01-0944.

10. Chang, J., Kalghatgi, G., Amer, A., and Viollet, Y., "Enabling High Efficiency Direct Injection Engine with Naphtha Fuel through Partially Premixed Charge Compression Ignition Combustion," SAE Technical Paper 2012-01-0677, 2012, doi: 10.4271/2012-01-0677.

11. Manente, V., Johansson, B., Tunestal, P., and Cannella, W., "Effects of Different Type of Gasoline Fuels on Heavy Duty Partially Premixed Combustion," SAE Int. J. Engines 2(2):71-88, 2010, doi: $10.4271 / 2009-01-2668$

12. Harvey, B., and Meylemans, H., "The role of butanol in the development of sustainable fuel technologies," J. Chem. Technol. Biotechnol. 86(1):1097-4660, 2011, doi: 10.1002/jctb.2540.

13. Cairns, A., Stansfield, P., Fraser, N., Blaxill, H. et al., "A Study of Gasoline-Alcohol Blended Fuels in an Advanced Turbocharged DISI Engine," SAE Int. J. Fuels Lubr. 2(1):41-57, 2009, doi: $10.4271 / 2009-01-0138$

14. Majer, V., and Svoboda, V., "Enthalpies of Vaporization of Organic Compounds: A Critical Review and Data Compilation,: Blackwell Scientific Publications, Oxford, pp:300, 1985

15. Ezeji, T., Qureshi, N., and Blaschek, H., "Bioproduction of butanol from biomass: from genes to bioreactors," Current Opinion in Biotechnology, 18(3):220-227, 2007, doi: 10.1016/j.copbio.2007.04.002.

16. Wasil, J, Johnson, J. and Singh, R, "Alternative Fuel Butanol: Preliminary Investigation on Performance and Emissions of a Marine Two-Stroke Direct Fuel Injection Engine," SAE Int. J. Fuels Lubr. 3(2): 1071-1080, 2010, doi: 10.4271/2010-32-0054

17. Valentino, G., Corcione, F., Iannuzzi, S., and Serra, S., "An Experimental Analysis on Diesel/n-Butanol Blends Operating in Partial Premixed Combustion in a Light Duty Diesel Engine," SAE Technical Paper 2012-01-1127, 2012, doi: 10.4271/2012-01-1127.

18. Abou-Rachid, H., El Marrouni, K., and Kaliaguine, S., "DFT studies of the hydrogen abstraction from primary alcohols by $\mathrm{O} 2$ in relation with cetane number data", Journal of Molecular Structure: THEOCHEM 631(1-3):241-250, 2003, doi: 10.1016/S0166-1280(03)00257-4.

19. Murphy, M., Taylor, J., and McCormick, R., "Compendium of Experimental Cetane Number Data," National Renewable Energy Laboratory, NREL/SR-540-36805, www.nrel.gov/vehiclesandfuels/pdfs/ sr368051.pdf, 2004

20. Manente, V., "Gasoline Partially Premixed Combustion". PhD thesis, Lund Institute of Technology, Lund University, Sweden, 2010.

21. Leermakers, C., Van den Berge, B., Luijten, C., Somers, L. et al., "Gasoline-Diesel Dual Fuel: Effect of Injection Timing and Fuel Balance," SAE Technical Paper 2011-01-2437, 2011, doi: 10.4271/2011-01-2437.

22. Manente, V., Johansson, B., Tunestal, P., and Cannella, W., "Influence of Inlet Pressure, EGR, Combustion Phasing, Speed and Pilot Ratio on High Load Gasoline Partially Premixed Combustion," SAE Technical Paper 2010-01-1471, 2010, doi: 10.4271/2010-01-1471.

23. Manente, V., Tunestal, P., Johansson, B., and Cannella, W., "Effects of Ethanol and Different Type of Gasoline Fuels on Partially Premixed Combustion from Low to High Load," SAE Technical Paper 2010-01-0871, 2010, doi: 10.4271/2010-01-0871.

24. Solaka, H., Aronsson, U., Tuner, M., and Johansson, B., "Investigation of Partially Premixed Combustion Characteristics in Low Load Range with Regards to Fuel Octane Number in a Light-Duty Diesel Engine," SAE Technical Paper 2012-01-0684, 2012, doi: 10.4271/2012-01-0684.

25. Leermakers, C., Somers, L., and Johansson, B., "Combustion Phasing Controllability with Dual Fuel Injection Timings," SAE Technical Paper 2012-01-1575, 2012, doi: 10.4271/2012-01-1575.

26. Leermakers, C., Bakker, P., Somers, L., de Goey, L. et al., "Commercial Naphtha Blends for Partially Premixed Combustion," SAE Technical Paper 2013-01-1681, 2013, doi: 10.4271/2013-01-1681.

\section{CONTACT INFORMATION}

C.A.J. Leermakers

Combustion Technology

Department of Mechanical Engineering

Eindhoven University of Technology

P.O. Box 513, Gem-N 1.21

5600 MB Eindhoven

The Netherlands

$\mathrm{T}+31402475995$

$\mathrm{F}+31402433445$

C.A.J.Leermakers@tue.nl

www.combustion.tue.nl

\section{ACKNOWLEDGMENTS}

This project was funded by the Dutch Technology Foundation STW (project 10417). DAF Trucks N.V., Shell Global Solutions, Avantium Chemicals B.V. and Delphi are also acknowledged for their contributions to the project. The authors kindly appreciate the support of the technicians of the Eindhoven Combustion Technology group: Hans van Griensven, Theo de Groot, Gerard van Hout and Bart van Pinxten. 


\section{APPENDIX}

\section{Fuel Analysis of n-butanol}

The coating of the gas chromatograph-mass spectrometer column might be relatively insensitive to polar molecules. The authors believe that a careful selection of column coating and GC settings could yield more detailed results. See Figure 20 and Table 6.

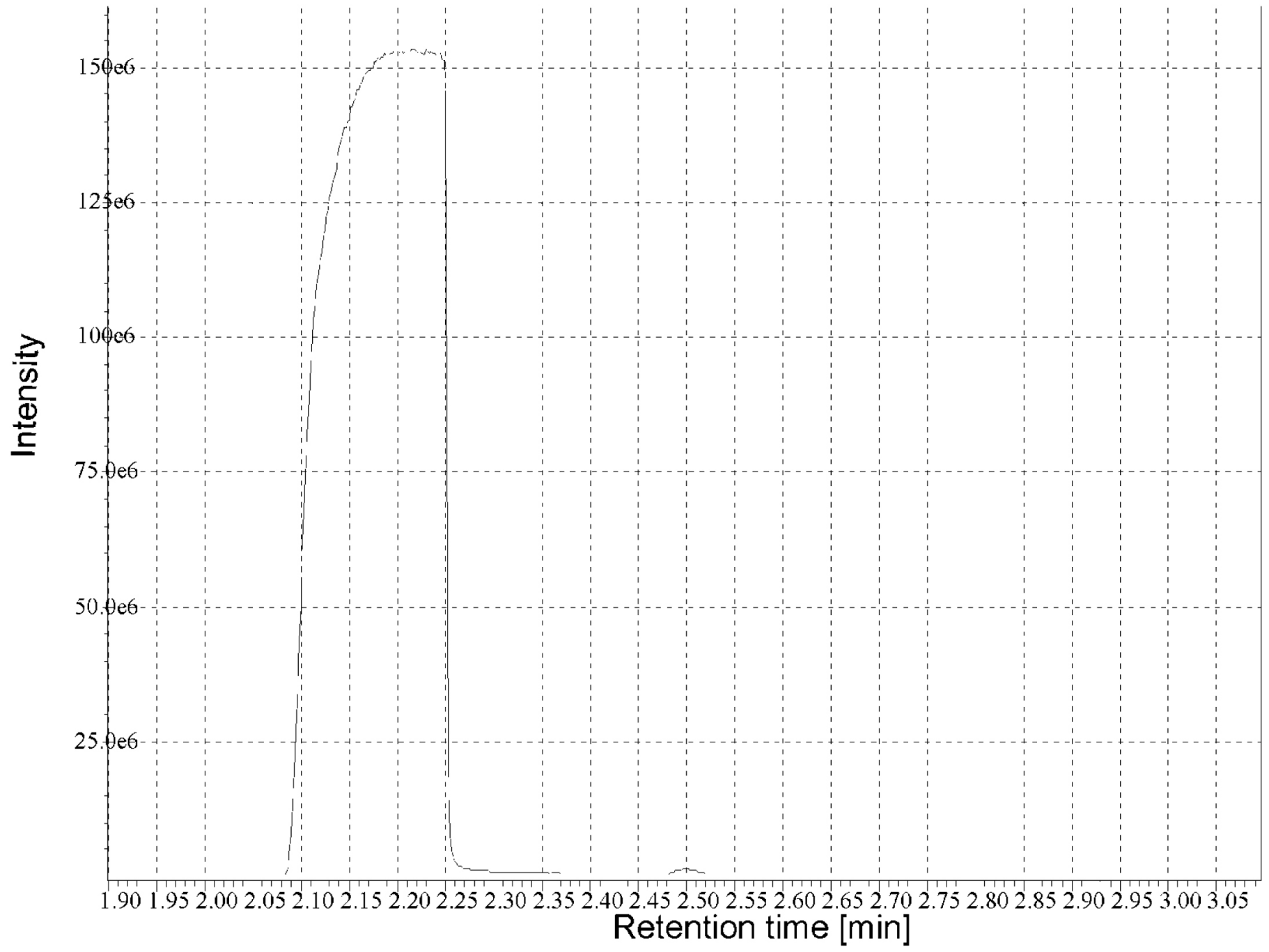

Figure 20. GC-MS Spectrum obtained for n-butanol

Table 6. Composition of n-butanol

\begin{tabular}{|l|l|l|l|}
\hline Name & Weight-\% & Time [min] & M [g/mole] \\
\hline 1-butanol & 99.87 & 2.15 & 74 \\
\hline 2-pentanol & 0.13 & 2.50 & 88 \\
\hline
\end{tabular}

